\title{
Reparación Directa: Mecanismo de Indemnización Integral de Perjuicios conforme a los Postulados de la Corte Interamericana de Derechos Humanos
}

\author{
Juan Felipe BarcoJaimes \\ Especialista en Derecho Administrativo, Universidad Santo Tomás-Bucaramanga (Colombia) \\ Abogado, Universidad Santo Tomás-Bucaramanga (Colombia) \\ Mail: juanfe90@hotmail.es \\ Paola Andrea Carrillo Hernández \\ Especialista en Derecho Administrativo, Universidad Santo Tomás-Bucaramanga (Colombia) \\ Abogado, Universidad Santo Tomás-Bucaramanga (Colombia) \\ E-mail: pandrea_9022@hotmail.com
}

\section{Resumen}

El presente escrito refleja la influencia que han tenido los pronunciamientos de la jurisdicción Contencioso Administrativo, especialmente el medio de control de reparación directa, con ocasión de los estándares fijados por la Corte Interamericana de Derechos Humanos en los casos donde se han presentado violaciones de derechos humanos.

Palabras clave: Reparación Directa, Daño, Perjuicio, Mecanismos de Resarcimiento, Verdad, Justicia, Reparación Integral y Garantía de No Repetición.

\begin{abstract}
This written present reflects the influence that the pronouncements of the jurisdiction have had Contentious Administratively across the (reparacióndirecta), the postulates of the Inter-American Court of Human rights
\end{abstract} in cases where they have presented violations of human rights.

Keywords: ReparaciónDirecta, Hurt, Prejudice, Mechanisms of Indemnity, Truth, Justice, Integral Repair and It Was guaranteeing of Not Repetition.

Résumé

Cette lettre reflète l'influence qu'ils ont eu les déclarations de la juridiction administrative, en particulier les moyens de commande de réparation directe, durant les normes établies par la Cour des droits de l'homme interaméricaine dans les cas où il ya eu des violations des droits de l'homme.

Mots-clés: Direct à Réparer les Dommages, les Blessures, Les Mécanismes d'indemnisation, La Vérité, La Justice, La Réparation et Aucunegarantie de Répétition. 



\title{
Reparación Directa: Mecanismo de Indemnización Integral de Perjuicios conforme a los Postulados de la Corte Interamericana de Derechos Humanos*
}

\author{
Juan Felipe BarcoJaimes \\ Paola Andrea Carrillo Hernández
}

\section{INTRODUCCIÓN}

El objetivo del presente escrito consiste en identificar el grado de influenciade los postulados de reparación integral que han sido desarrollados por la Corte Interamericana de Derechos Humanos sobre algunos de los pronunciamientos efectuados por la Jurisdicción de lo Contencioso Administrativoa través del medio de control de reparación directa.

Para ello, se utiliza elenfoque de investigación cualitativo, toda vez que se parte de la revisión de múltiples documentos respecto al reconocimiento de perjuicios derivados de la responsabilidad extracontractual del Estado y de la responsabilidad internacional del Estado, se efectúa un análisis de la normatividad y la jurisprudencia, y con base en ello, se intenta determinar el grado de influencia en algunos de los pronunciamientos efectuados por el Consejo de Estado en cuanto a la restitutio in integrum.

Así las cosas, el desarrollo de la investigación se adelanta en tres etapas: en primer lugarse revisa la responsabilidad extracontractual del Estado desde el fundamento constitucional y su historia, seguidamente se revisan los postulados que ha definido la Corte Interamericana de Derechos Humanos en cuanto a la obtención de una indemnización integral de perjuiciosylos últimos pronunciamientos proferidos por el Consejo de Estado relativos al reconocimiento integral de perjuicios a través de la acción de reparación

* El texto aquí presentado surgió en desarrollo de la investigación titulada "La reparación directa como mecanismos de resarcimiento integral de perjuicios conforme a los parámetros establecidos por la Corte Interamericana de Derechos Humanos" realizado por Juan Felipe Barco Jaimes, Paola Andrea Carrillo Hernández, Martha Lucía González Gómez, Mari Andrea Ortiz Sepúlveda, en desarrollo de la Especialización en Derecho Administrativo, Cohorte XIX, Universidad Santo Tomás, Bucaramanga (Colombia). 
directa ${ }^{1}$,y por último, se concluye si ha tenido o noinfluencia los parámetros de reparación establecidos por el Juez del Sistema Regionalen diferentes Sentencias de la jurisdicción contencioso administrativa donde se estudia una posible afectación y desconocimiento a los derechos humanos.

Lo anterior, con el fin de dotar de mecanismos o de herramientas que sean útiles para los abogados y los operadores de justicia, a la hora de solicitar y reconocer medidas indemnizatorias a favor de las víctimas que se vean afectadas por la acción u omisión de los agentes estatales, y que contemplen una reparación integral que abarque todos los aspectos físicos, morales, culturales y sociales en los que se vean afectados.

\section{DE LA RESPONSABILIDAD EXTRACONTRACTUAL DEL ESTADO}

La Constitución Política de 1991 establece que Colombia es un Estado Social de Derecho fundado en el respeto a la dignidad humana, el cual tiene como fin servir a la comunidad y proteger a todas las personas residentes en Colombia, en su vida, honra, bienes, creencias, y demás derechos y libertades, en aras de asegurar el cumplimiento de los deberes sociales del Estado y de los particulares.

Es por ello que la Carta Magna señala en su Artículo 90 que el Estado debe responder patrimonialmente por los daños antijurídicos que le sean imputables con ocasión de la acción u omisión de sus autoridades públicas, derivando así, la denominada responsabilidad extracontractual en cabeza del Estado.

En desarrollo del Artículo 90 de la Constitución Política de Colombia, el poder legislativo ha instituido mecanismos judiciales mediante los cuales se puede pretender el reconocimiento de perjuicios por las acciones, hechos, omisiones y demás circunstancias en las que se vea comprometida la responsabilidad del Estado; uno de estos medios jurídicos es el medio de control de reparación directa ${ }^{2}$, siendo

1 La Comisión Redactora de Nuevo Código de Procedimiento Administrativo y de lo Contencioso Administrativo -CPACA- (Ley 1437 de 2011) cambió la denominación de acción por medio de control; no obstante lo anterior, debe precisarse que el titulo XI del Decreto 01 de 1984 se denomina "Medios de Control", por lo tanto se considera que dicho cambio no constituye una novedad. Al respecto, la Dra. Valle De la Hoz (2012) precisa "En la actualidad, los medios de control antes mencionados se encuentran determinados en varios de los títulos del Código Contencioso Administrativo, entre ellos el denominado Medios de Control, que incluye las acciones de simple nulidad, nulidad y restablecimiento del derecho, reparación directa, repetición, y controversias contractuales"'( p.146).

2 Al respecto, Valle De la Hoz Olga Mélida (2011) en su escrito "Medios de Control” señala: "Este medio de control tiene su fuente directa en el Artículo 90 de la Constitución Política, en razón a que es éste precepto el que le impone al Estado la obligación de responder patrimonialmente por los daños antijurídi-cos causados con motivo de la acción u omisión de las autoridades públicas. Cuando la causa del daño sea un hecho, una omisión, una operación administrativa o la ocupación temporal o permanente de un inmueble por causa de trabajos públicos, el Estado deberá repararlo siempre que sea imputable a una entidad pública o a un particular que haya obrado siguiendo instrucciones de un ente público". 
utilizado como herramienta para el restablecimiento por los perjuicios que se causen por parte del Estado a sus administrados.

\subsection{Evolución de la responsabilidad extracontractual del Estado}

Con el fin de desarrollar el tema, es importante efectuar un corto recuento histórico en lo que respecta a la evolución de la responsabilidad extracontractual del Estado a nivel general, para después determinar cómo han influido las decisiones de la Corte Interamericana de Derechos Humanos dentro del marco de responsabilidad en el del ordenamiento jurídico colombiano.

Para tal efecto, fueron consultados autores como el doctrinante Libardo Rodríguez en su texto "Derecho Administrativo General y Colombiano" quien ha precisado que, la responsabilidad estatal ha atravesado por diversas etapas en su evolución, en las que inicialmente, el Estado no era responsable por los daños que se llegaren a ocasionar en el ejercicio de su actividad ${ }^{3}$, para posteriormente abordar una etapa que denomina "responsabilidad", y finalizar con una "responsabilidad creciente", la cual señala que se origina a partir del fallo blanco, y consiste en la tendencia a aumentar la responsabilidad del Estado.

Otro de los autores consultados al respecto es el Dr. Gustavo Quintero Navas (2009) quien en su escrito denominado "La Construcción de la Responsabilidad del Estado en Colombia: Entre la Dualidad de Jurisdicciones y la Dualidad Jurídica" ha señalado que con anterioridad a la creación de una jurisdicción especial encargada de adelantar los procesos en los que se viera involucrado el actuar de la administración, existía una responsabilidad de las personas públicas dentro de un monismo jurisdiccional, situación que fue modificada con la adopción del Fallo Blanco (1873), en el que se concretó que la responsabilidad del Estado por el hecho de las personas que emplean un servicio público, no puede regirse bajo los principios establecidos por el Código Civil, referentes a las relaciones entre particulares, por lo que se hizo indispensable la creación de una instancia especial que conociera de dichos asuntos.

Por tal razón, es posible referirse a un dualismo jurisdiccional, figura que tuvo su origen en el Derecho francés y que fue adoptado por el ordenamiento jurídico colombiano.

Ahora bien, en lo que respecta a la evolución de la responsabilidad estatal dentro del ordenamiento jurídico colombiano, el Dr. Libardo Rodríguez (2007) ha concretado la existencia de etapas, las cuales se pueden sintetizar así:

3 Sin embargo, esta idea de irresponsabilidad no era absoluta, al encontrarse que: 1. los daños producidos en la actividad estatal, eran atribuibles a los agentes que los causaban; 2. El Estado era responsable en las situaciones que la ley expresara y, 3. El Estado era irresponsable frente a los daños causados por su actividad de poder, pero respondía por los perjuicios ocasionados en su actividad de gestión. (Rodríguez, 2007, p. 494). 
1.1.1. Etapa de aplicación del derecho privado: Una vez reconocida la responsabilidad del Estado dentro del ordenamiento jurídico colombiano, la misma fue asimilada con la responsabilidad en cabeza de los particulares, especialmente, la atribuida a las personas jurídicas privadas (Rodríguez, 2007, p.497).

1.1.2. Etapa de transición: La Corte Suprema de Justicia comienza a dar aplicación a las teorías de la Culpa, falta o falla del servicio, a la hora de hablar de responsabilidad del Estado. Dicha situación, conllevó a que se analizara si la responsabilidad del Estado podía manejarse dentro del mismo régimen en que se atribuía la responsabilidad a los particulares, y conforme a los parámetros del Código Contencioso Administrativo para la época, el Consejo de Estado terminó conociendo de la responsabilidad por trabajos públicos, aplicando la teoría de la culpa o falla del servicio. (Rodríguez, 2007, p. 500).

1.1.3. Etapa de aplicación del derecho público: Con la expedición del Decreto 528 de 1964, se le atribuyó la competencia a la Jurisdicción de lo Contencioso Administrativo para conocer de los asuntos donde se debata la responsabilidad de la Administración, exceptuando los asuntos donde se ventilaran cuestiones de derecho privado (Rodríguez, 2007, p. 502).

Es así como con la implementación de una jurisdicción especializada en resolver los asuntos en los que se vea inmiscuida la responsabilidad del Estado, se implementaron los respectivos regímenes con fundamento en los postulados y normas de derecho público que permiten atribuir responsabilidad por los hechos que conlleven daño en los particulares y en los que se vea involucrado el actuar de la administración.

\section{POSICIÓN DE LA CORTE INTERAMERICANA DE DERECHOS HUMANOS FRENTE A LA INDEMNIZACIÓN INTEGRAL DE PERJUICIOS}

Al respecto, antes de iniciar con el estudio de los postulados adoptados por la Corte Interamericana de Derechos Humanos - CIDH -, es importante precisar que este Tribunal Internacional ha empleado el término de reparación como el proceso mediante el cual se pretende remediar a las víctimas de la acción u omisión del Estado.

Es así como, al definir el concepto de "reparaciones", señala que el mismo consiste en un"término genérico que comprende las diferentes formas como un Estado puede hacer frente a la responsabilidad internacional en que ha incurrido" (CIDH. Caso Garrido y Baigoria. Reparaciones párr. 41; Caso Paéz. Reparaciones. 
Párr. 48); lo anterior, debido a que no se puede estandarizar una compensación, pues debe analizarse cada caso en concreto y determinar el detrimento ocasionado.

Por tanto, con la reparación se pretende volver a su estado inicial todo aquello que fue afectado o lesionado con la infracción del Estado; sin embargo, si bien es cierto a través de la indemnización se pretende mitigar el daño ocasionado, nunca se podrá hablar de una reparación absoluta, toda vez que existen casos en las que sea imposible retrotraer las situaciones, circunstancias o derechos al estado anterior a la ocurrencia de la afectación ${ }^{4}$.

Frente a este aspecto, la doctrinante Deissy Motta Castaño (2010) en su Artículo "Responsabilidad del Estado Colombiano frente al derecho a la reparación en el Sistema Interamericano de los Derechos Humanos: protección y garantía de la escritura", destaca que la reparación integral de perjuicios implementada por la Corte Interamericana de Derechos Humanos busca proporcionar a la víctima un equilibrio, en el que no sólo se pretenda una indemnización económica, sino que se busque una reivindicación por parte del Estado a través de actos como disculpa o perdón, actos de desagravio, becas de estudio, educación en Derechos Humanos de funcionarios estatales, acciones orientadas a la no repetición, sanción de los responsables de los hechos, entre otros, por medio de los cuales la administración acepta su responsabilidad y resarce los perjuicios ocasionados a sus víctimas (Motta Castaño 2010, p. 13).

Teniendo en cuenta lo anterior, toma importancia efectuar un recuento de algunos de los pronunciamientos en los que se ha encontrado responsable al Estado Colombiano por la afectación de los derechos humanos y se han implementado mecanismos de indemnización tendientes a obtener una reparación integral de perjuicios.

Es así como la Corte Interamericana de Derechos Humanos en una de sus decisiones ${ }^{5}$, encontró responsable al Estado Colombiano por la afectación de derechos Humanos, pese a haberse adelantado las investigaciones y el respectivo trámite jurisdiccional, obteniendo pronunciamientos judiciales en los que se declara la afectación de los mencionados derechos; en el caso en cuestión, se encontró que miembros del Cuerpo Especial Armado de la Policía Nacional y del Ejercito Nacional en hechos ocurridos el día 23 de enero de 1991, ejecutaron extrajudicialmente a un grupo de población civil mientras se encontraban bajo su custodia bajo el argumento que los mismos pertenecían a un grupo subversivo sin que dicha situación fuese cierta; igualmente, destacó que se ejecutaron acciones ${ }^{6}$ tendientes a alterar las circunstancias en que ocurrieron los hechos y obstaculizar las investigaciones adelantadas con el fin de esclarecer los hechos (CIDH, 2002, párr. 2).

4 Como lo es el derecho a la vida o el daño psicológico de una víctima.

5 Caso Las Palmeras Vs. Colombia.

6 Dichas acciones consistieron en el cambio de prendas de vestir de los cuerpos por prendas de uso militar, la incineración de las prendas de vestir de las víctimas, el traslado de los cuerpos a las instalaciones de la morgue del Hospital de Mocoa sin el respeto de los protocolos de recolección probatoria, entre otras. 
Asimismo, destaca que dentro de las víctimas se encontró una persona que no pudo ser identificada por lo que dispuso que debía efectuarse una reparación de los perjuicios causados a los familiares de esta víctima, a quienes se les otorgó el término de 24 meses contados a partir de la identificación de la víctima, para reclamar la indemnización a que tienen derecho, previo a presentarse los elementos probatorios que permitan deducir el vínculo de parentesco o lazo afectivo.

Igualmente, determinó la indemnización de perjuicios de las víctimas del presente asunto, reconociendo los perjuicios de índole inmaterial y teniendo derecho a los mismos, según el vínculo de parentesco con la víctima directa.

Sumado a lo anterior, se garantizaron otros medios de restablecimiento de perjuicios, en los que se pretendió dar cumplimiento al postulado de la Restitutio in Integrum, entendido este como el deber de garantizar una indemnización que satisfaga a cabalidad la afectación ocasionada en las víctimas con la comisión del hecho que transgredió los derechos humanos ${ }^{7}$.

A su vez, la Corte Interamericana de Derechos Humanos en Sentencia del 5 de julio de $2004^{8}$, efectuó pronunciamiento respecto a los hechos ocurridos el día 06 de octubre de 1987 en el Municipio de Puerto Boyacá - Departamento de Boyacá, en los que se produjo la detención, desaparición y ejecución de 19 comerciantes que se desplazaban de la ciudad de Cúcuta hacia Medellín, encontrando que el Estado Colombiano es responsable por la afectación a los derechos a la Libertad Personal, el Derecho a la Integridad Personal y el Derecho a la Vida, toda vez que, dichas acciones fueron ejecutadas por miembros del Ejército Nacional e integrantes de un grupo paramilitar que comandaban la zona (CIDH, 2004, párr. 2).

Destaca que con la desaparición de los 19 comerciantes, las víctimas o familiares sufrieron daños tanto materiales como inmateriales aunados a la falta de apoyo por parte de las autoridades estatales (para buscar a sus familiares y protección frente a quienes realizaban labores de búsqueda); además, se omitió brindar una atención a la salud física y psicológica de los mismos, respecto de la afectación que se produjo con la forma inhumana en que fueron desaparecidas las víctimas directas y el reconocimiento de una adecuada indemnización dentro del ordenamiento jurídico interno al haberse adelantado los trámites jurisdiccionales sin que se haya efectuado pronunciamiento alguno.

7 Se tomaron como medidas de reparación integral de perjuicios las siguientes: Derecho a la verdad: obligación del Estado en adelantar las labores de investigación, identificación, juzgamiento y sanción a los autores del hecho, a efectos de garantizar el derecho al acceso a la justicia; realizar las labores de identificación y establecer el paradero de los restos mortales de la persona no identificada, además de exhumar los mismos y hacer entrega a los familiares para que ellos den una adecuada sepultura, gastos que deben ser acarreados por el Estado Colombiano. Lo anterior, debe ejecutarlo dentro de un plazo razonable; realizar las gestiones tendientes a la ubicación de los familiares de la persona no identificada; y, la publicación de la Sentencia de fondo dictada dentro de la jurisdicción interna y de la Sentencia Proferida por la CIDH.

Caso 19 comerciantes vs. Colombia. 
Por ello, a efectos de garantizar una adecuada indemnización, se efectuó el reconocimiento de perjuicios materiales, perjuicios inmateriales, teniendo en cuenta para ello la presunción del perjuicio en los hijos, cónyuge o compañera, padres y hermanos, quienes no tienen la carga probatoria en demostrar el vínculo afectivo existente con la víctima.

Finalmente, se observa en la decisión, la adopción de medidas resarcitorias tendientes a garantizar la indemnización integral de perjuicios ${ }^{9}$, buscando brindar una atención adecuada a los sujetos pasivos de las conductas en las que se ven inmiscuidas la afectación a los derechos humanos.

Otro pronunciamiento realizado por la Corte Interamericana de Derechos Humanos es el contenido en la Sentencia de fecha 12 de septiembre de $2005^{10}$, en el que se efectuó un estudio por los hechos ocurridos el día 24 de agosto de 1994, donde agentes Estatales y un particular privaron la libertad del señor Wilson Gutiérrez Soler quien sufrió actos de tortura y coacción a fin de obtener una confesión, respecto de la cual el señor Gutiérrez Soler fue declarado inocente por la justicia interna (CIDH, 2005, párr. 2).

En el caso en comento, el Máximo Tribunal de Derechos Humanos consideró que existe responsabilidad por parte del Estado Colombiano al haberse efectuado una detención sin previa orden escrita de autoridad competente o que se estuviere cometiendo una conducta ilícita en flagrancia. Lo anterior, por cuanto el funcionario estatal y el particular citaron a la víctima a un lugar específico, donde se produjo su detención, fue conducido a las instalaciones donde funcionaba una entidad pública y fue sometido a torturas, pretendiendo que éste hiciera una confesión en ausencia de un representante legal o defensor público que velara por su derecho a la defensa.

Pese a haberse iniciado las labores de investigación dentro del ordenamiento interno, encuentra la Corte que no se adelantaron las medidas tendientes a sancionar los actos de tortura.De esta forma, no se cumplió con el deber de los Estados en investigar y sancionar a los autores de las conductas que transgredan los derechos humanos.

Igualmente, quedó demostrada la afectación psíquica y moral que padeció la víctima directa y sus familiares, teniendo en cuenta que las condiciones de seguridad fueron mínimas, ante las amenazas elevadas contra ellos, al haberse presentado las denuncias respectivas ante la ocurrencia de los hechos, situación frente a la cual,

9 Medidas de indemnización de perjuicios adoptadas: búsqueda de familiares en los casos donde no se pudo identificar plenamente a las víctimas directas, a efectos de hacer entrega de la indemnización por el daño inmaterial; derecho a la verdad: obligación del Estado en adelantar las labores de investigación, identificación, juzgamiento y sanción a los autores del hecho; obligación de búsqueda de los restos mortales; monumento en memoria de las víctimas; acto público de reconocimiento de responsabilidad internacional y de desagravio a los familiares de los 19 comerciantes; otorgamiento de tratamiento médico a los familiares y, se efectuó una condena en costas y gastos del trámite procesal.

10 Caso Gutiérrez Soler vs. Colombia. 
se efectúa una indemnización de índole material, el reconocimiento de un daño inmaterial $^{11}$ y se ordena la realización de las acciones pertinentes, tendientes a garantizar una indemnización integral de perjuicios ${ }^{12}$ a favor de la víctimas directa e indirectas de la situación descrita.

Asimismo, en la Sentencia ${ }^{13}$ proferida el día 15 de septiembre de 2005 con ocasión de los hechos ocurridos entre el 15 y 20 de julio de 1997 en inmediaciones del Municipio de Mapiripán - Departamento del Meta, donde miembros de las autodefensas unidas de Colombia con colaboración de agentes estatales, privaron de la libertad, torturaron y asesinaron cerca de 49 civiles, desapareciendo sus cuerpos y arrojando los restos al Río Guaviare (CIDH, 2005, párr. 2).

En este sentido, destaca la Corte la responsabilidad que tienen los Estados en garantizar la protección de la población civil, encaminada a impedir que terceros cometan acciones violentas contra dichas personas que constituyan una afectación a los derechos humanos, además de encontrar que la masacre fue cometida en una situación de desprotección de los civiles frente a las condiciones de conflicto armado del país.

Por lo anterior, se incurrió en la vulneración de los derechos humanos a la vida, integridad personal y libertad personal de las víctimas directas como de sus familiares quienes han padecido afectación psicológica y angustia por la masacre y tortura de sus seres queridos, aunado al desplazamiento forzado del que fueron objeto y el desconocimiento del paradero de los restos mortales de las víctimas.

Igualmente, los Estados están en la obligación de garantizar los recursos judiciales efectivos que permitan un restablecimiento integral de los perjuicios ocasionados a las víctimas de violaciones de derechos humanos, situación que no ocurrió en el caso en concreto, pese a haberse iniciado el respectivo trámite ante las jurisdicciones penal militar, contencioso administrativo, procedimientos administrativos, justicia penal ordinaria y respecto de los cuales transcurrido un tiempo prolongado, no se obtuvo condena alguna que sancionara a los responsables de las conductas y restableciera los derechos de los afectados.

Es por ello que se realizó un reconocimiento de los perjuicios materiales e inmateriales a las víctimas por los hechos de la Masacre de Mapiripán y se

11 Encontrando la afectación al proyecto de vida, teniendo en cuenta que los padecimientos de la víctima directa conllevaron al desequilibrio de los proyectos, metas y planes trazados como metas personales.

12 Las medidas de reparación integral adoptadas en el presente caso fueron: derecho a la verdad: obligación del Estado en adelantar las labores de investigación, identificación, juzgamiento y sanción a los autores del hecho; tratamiento médico y psicológico; publicación de las partes pertinentes de la Sentencia; difusión y aplicación de la Jurisprudencia del Sistema Interamericano de Derechos Humanos en la Justicia Penal Militar; implementación de los parámetros del Manual para la investigación y documentación eficaces de la tortura y otros tratos o penas crueles, inhumanos o degradantes ("el Protocolo de Estambul"); fortalecimiento de los controles en centros de detención y, se efectuó una condena en costas y gastos del trámite procesal.

13 Caso Masacre de Mapiripán Vs. Colombia. 
establecieron mecanismos para la obtención de una indemnización integral de perjuicios $^{14}$.

Como último pronunciamiento objeto de estudio, debe señalarse el efectuado por la Corte Interamericana de Derechos Humanos el día 01 de julio de $2006^{15}$, en el que se estudiaron los hechos ocurridos en junio de 1996 y a partir de octubre de 1997 en los corregimientos de La Granja y el Aro del Municipio de Ituango - Antioquia, donde miembros de la Fuerza Pública en colaboración con un grupo de paramilitares, realizaron incursiones armadas en las que se asesinaron miembros de la población civil, quienes se encontraban en estado de indefensión, despojándolos de sus bienes y fomentando el desplazamiento de la zona por parte de sus habitantes (CIDH, 2006, párr. 2).

Respecto a las incursiones militares efectuadas en el Municipio de Ituango, encontró la Corte Interamericana de Derechos Humanos que se presenta una afectación a los derechos protegidos por la misma, toda vez que el Estado Colombiano no ejerció las labores tendientes a la protección de derechos humanos, participando en dichas tomas a población civil y no garantizó el derecho a la verdad, justicia y reparación a las víctimas y sus familiares.

Dadas las condiciones en que se efectuó la toma armada, es decir, teniendo en cuenta que no se pudo establecer los ingresos devengados por la totalidad de las víctimas, las condiciones de destrucción de las viviendas, entre otros, la Corte Interamericana de Derechos Humanos señaló montos en equidad respecto al reconocimiento de dicho perjuicio. Asimismo, en aras de resarcir la totalidad de perjuicios causados, ha tomado medidas como la adopción de planes de educación, adjudicación de viviendas, planes de salud, entre otras ${ }^{16}$, que pretenden restablecer los derechos de las víctimas y llevarlas a las condiciones de dignidad y respeto, características de los derechos humanos.

14 Derecho a la verdad: obligación del Estado en adelantar las labores de investigación, identificación, juzgamiento y sanción a los autores del hecho; identificación de las víctimas de la masacre y de sus familiares; establecer un mecanismo que permita realizar el seguimiento oficial de las reparaciones ordenadas; garantías estatales de seguridad para los ex habitantes del municipio de Mapiripán que decidan regresar; ofrecer disculpas públicas y el reconocimiento de la responsabilidad internacional por parte del Estado; construcción de monumentos en memoria de las víctimas; capacitar educativamente a las fuerzas públicas en aspectos relacionados con la protección de los derechos humanos.

15 Caso Ituango Vs. Colombia.

16 Reconocimiento del daño inmaterial con ocasión de la privación de la vida de algunas víctimas, reiterando la presunción de afectación que se ha manejado en cuanto a este perjuicio; derecho a la verdad: obligación del Estado en adelantar las labores de investigación, identificación, juzgamiento y sanción a los autores del hecho; tratamiento adecuado a los familiares de las víctimas; garantías estatales de seguridad para los ex habitantes del municipio de Ituango que decidan regresar; disculpa pública y reconocimiento de responsabilidad internacional; programas de Vivienda; fijar una placa en un lugar público de los corregimientos afectados para que futuras generaciones conozcan los hechos que dieron origen al caso; implementación de educación en Derechos Humanos a las Fuerzas Militares, por ser quienes ejercieron ataquen contra la población civil; publicación de las partes pertinentes de la Sentencia. 
A modo de conclusión, puede afirmarse que la Corte Interamericana de Derechos Humanos ha establecido postulados aplicables en cuanto a la afectación de derechos humanos se trata, tendientes a la obtención de una indemnización integral de perjuicios que no se limite tan sólo al reconocimiento de un valor económico por concepto de perjuicios materiales e inmateriales, sino que vaya más allá y establezca un adecuado tratamiento a las víctimas, haciendo efectivos los derechos a la verdad, justicia, reparación y garantías de no repetición.

Es así como, se han adoptado medidas de tipo simbólico como lo son la construcción de monumentos en honor a las víctimas, el pedir excusas públicas por parte del Estado, el reconocimiento de responsabilidad por parte de las entidades estatales que transgredieron los derechos de las víctimas, el brindar tratamientos sicológicos y médicos a las víctimas indirectas de los hechos, capacitaciones respecto a la protección de derechos humanos, entre otras, tendientes a proporcionar a los sujetos cuyos derechos han sido afectados, una indemnización de tipo inmaterial, la cual, sumada al reconocimiento de índole económico, pretende otorgar a las víctimas una indemnización integral de perjuicios, cumpliéndose con los postulados de la Corte Interamericana de Derechos Humanos en cuanto a la protección de los mismos se refiere.

\subsection{Desarrollo Jurisprudencial del Consejo de Estado frente a la Reparación Integral de Perjuicios a través del medio de control de Reparación Directa}

El Estado colombiano como persona jurídica tiene la obligación de garantizar la protección a los habitantes del territorio nacional, deber que conlleva por sí mismo la obligación de responder patrimonialmente por los daños que se causen a aquellos (Alviar, 2009, p. 234).

Atendiendo a la obligación que tiene elEstado de reparar los daños ocasionados a personas que no están en la capacidad jurídica de soportarlo,serevisará cronológicamente algunos de los últimos pronunciamientos proferidos por el Consejo de Estado relativos al reconocimiento integral de perjuicios a través de la acción ${ }^{17}$ de reparación directa.

Frente a ello, en Sentencia del 1 de febrero de $2011^{18}$, se estudió la responsabilidad extracontractual del Estado por hechos en los que el agente de la policía Luis Alberto Marin García se dirigía a la estación de Policía de San Calixto (Norte de Santander) en cumplimiento del traslado que le había sido ordenado por su superior, y sin embargo, no pudo llegar al destino, toda vez que miembros del Ejercito de Liberación Nacional -ELN- incursionaron

17 Teniendo en cuenta que los hechos y la demanda fue presentada en vigencia del Codigo Contencioso Administrativo-CCA- Decreto 01 de 1984

18 Consejo de Estado - Sección Tercera - Radicación 54001-23-31-000-1994-08357-01(21274) CP. Jaime Orlando Santofimio Gamboa. 
en la buseta en la que él se movilizaba y lo asesinaron al ser identificado como miembro de la Policía Nacional.

En esta Sentencia, el Honorable Consejo de Estado argumenta la imputación frente al Estado al considerar que no se tomaron las medidas de protección necesarias y por tal razón el Estado se hace responsable, pues no se puede obligar a un ciudadano en cumplimiento de un deber a soportar un daño antijurídico que no está en capacidad de soportar.

En esta providencia, el máximo Tribunal Contencioso Administrativo adoptó las siguientes medidas de reparación:

- Ordenó a la Fiscalía General de la Nación que informara acerca de la investigación penal adelantada por el homicidio de Luis Alberto Marín y se informe a sus familiares por un medio de comunicación.

- Ordenó al Director General de la Policía Nacional para que mediante una circular que debía distribuirse en todos los departamentos, estaciones y subestaciones de la institución, se informara y se actualizara la forma en que deben aplicarse los procedimientos para la realización de los desplazamientos, garantizando todas las medidas disponibles y razonables de seguridad.

- $\quad$ Ordenó a la Dirección General de la Policía que realizara un curso en el Departamento de Policía de Norte de Santander dirigido a los oficiales y sub-oficiales de la institución, en el que ofreciera la formación relacionada con los deberes de los miembros de la fuerza pública en tiempos de conflicto armado, la protección de los civiles y el respecto del derecho internacional humanitario.

Posteriormente, en Sentencia del 14 de septiembre de $2011^{19}$, el Consejo de Estado centró su estudio en analizar la responsabilidad por la falla en el servicio al no señalizar los lugares en los que las minas antipersonales habían sido instaladas por el Ejército Nacional y como consecuencia, un joven que se encontraba prestando el servicio militar obligatorio sufrió graves lesiones y entre ellas perdió su pierna derecha.

En la providencia referida, se hace un estudio detallado del daño a la salud, respecto del cual, se acepta el reconocimiento del mismo como un nuevo perjuicio inmaterial, diferente al moral y adopta un nuevo modelo para resarcir económicamente a la víctima por la pérdida corporal que ha padecido. Igualmente, deja abierta la posibilidad a otras formas de daño y frente a ellas sus diferentes formas de reparación, las cuales dependiendo del estudio de la afectación deberán ser reconocidas.

19 Consejo de Estado - Sección Tercera - Radicación 05001-23-25-000-1994-00020-01(19031) M.P Enrique Gil Botero. 
Ahora bien, en Sentenciaadiada el 26 de octubre de $2011^{20}$, en el cual los hechos que dieron origen a la responsabilidad del Estado fueron la detención y posterior muerte de los señores Jhon Freddy Arenas y Luís Fernando Hernández Carvajal y la detención y las lesiones ocasionadas a los señores Luís Felipe Rendón González y Deison Alberto Rodríguez por parte de agentes de la Policía Nacional, el Consejo de Estado consideró procedente otorgar una forma de reparación que denominó" "medidas de reparación integral'basándose en el Bloque de Constitucionalidad.

En está providencia, el Máximo Tribunal de lo Contencioso Administrativo consideró que de acuerdo con las normas y la jurisprudencia nacional e internacional, el Estado colombiano estaba en la obligación de respetar y garantizar los derechos humanos y de acuerdo a ello, declaró la responsabilidad patrimonial de la Nación Ministerio de Defensa-Policía Nacional por la detención y muerte de los señores John Freddy Arenas y Luis Fernando Hernández Carvajal y por la detención y lesiones ocasionadas a los señores Luis Felipe Rendón González y Deisón Alberto Rodríguez Patiño en hechos ocurridos el 15 de agosto de 1992 y ordenó:

- Realizar una publicación, en un medio escrito de amplia circulación nacional y en uno de amplia circulación local en el departamento de Antioquia con una reseña completa de la Sentencia.

- Ordenó al Ministro de Defensa en compañía de los altos mandos militares, celebrar una ceremonia con la presencia de los demandantes, la participación de la comunidad e invitación a los medios de comunicación del departamento de Antioquia, con el fin que se ofrecieran disculpas públicas a los ofendidos y a la comunidad por la muerte de los señores Jhon Fredy Arenas y Luis Fernando Hernández Carvajal y retención y lesiones de los señores Luis Felipe Rendón González y Deyson Alberto Rodríguez Patiño.

- Ordenó oficiar a la Fiscalía General de la Nación para que reabriera la investigación penal adelantada ante la justicia penal militar con fines de justicia y no repetición por estar configurado un delito de esa humanidad.

Asimismo, en Sentencia del dieciocho (18) de enero de dos mil doce (2012) ${ }^{21}$, el Honorable Consejo de Estado estudió la responsabilidad del Estado frente a la muerte violenta del abogado Javier Alberto Barriga Vergel, y condenó a la Nación por no haberle brindado las medidas de protección, máxime cuando se tenía conocimiento del peligro que estaba sometido la víctima.

En este proveído, el H. Consejo de Estado señaló frente a las medidas de reparación no pecuniarias,que existe una diferenciafrente a la reparación de víctimas de

20 Consejo de Estado - Sección Tercera - Radicación 31-000-1993-01886-01 (18850), M.P: Stella Conto Diaz del Castillo.

21 Consejo de Estado - Sección Tercera - Radicación 54001-23-31-000-1997-02780-01 (19959) M.P: Jaime Orlando Santofimio Gamboa. 
violaciones de Derechos Humanos y víctimas de otro tipo de vulneraciones o daños, pues frente a estos últimos no contempla medidas simbólicas, conmemorativas, de rehabilitación o de no repetición, lo cual no implica que no se repare íntegramente el perjuicio.

En esa oportunidad, el Consejo de Estado ordenó como medidas de reparación integral:

- Ordenó la realización de un acto público en el que el Director del Departamento de la Policía de Norte de Santander ofreciera disculpas a los familiares de Javier Alberto Barriga Vergel.

- Ordenó publicar la parte resolutiva de la Sentencia en todas las Estaciones de la Policía Nacional en el Departamento de Norte de Santander por un período de seis (6) meses, y comunicarla a través de los diferentes medios de comunicación de circulación departamental.

- Ordenó compulsar copias ante las autoridades competentes para que se estudie si hay lugar o no a iniciar las investigaciones tanto disciplinarias, como penales en contra de aquellos funcionarios de la Policía Nacional, o del Ejército Nacional que en la época de los hechos no contribuyeron a la protección de la seguridad personal de la víctima.

- OrdenóA la Fiscalía General de la Nación informar acerca de los resultados de las investigaciones adelantadas por el homicidio del abogado Javier Alberto Barriga Vergel.

Otro pronunciamiento para destacar, es la Sentencia del 18 de enero de 2012 22 , en un caso similar al anterior, en el que se estudiaba la responsabilidad del Estado por la muerte del político Feisal Mustafa Barbosa quien fue retirado de una reunión política, la cual presidía y posteriormente fue asesinado por parte del ELN.

En la providencia en comento, el Consejo de Estado resalta el deber positivo derivado de la posición de garante por parte del Estado para determinar la responsabilidad por los perjuicios ocurridos a los familiares del Dr. Mustafa Barbosa.

Por tanto, de acuerdo al proveído en mención, la causal de exoneración de responsabilidad por hecho de un tercero sólo opera como eximente de responsabilidad si analizadas las demás circunstancias no era previsible para el Estado en su posición de garante defender y garantizar los derechos humanos de las personas puestas en situación de peligro.

En esta providencia el Consejo de Estado ordenó:

- $\quad$ La realización de un acto público en el que el Ministro de Defensa y el Director del Departamento de la Policía de Santander ofrezca disculpas a los familiares de Feisal Mustafá Barbosa.

22 Consejo de Estado - Sección Tercera - Radicación 68001-23-15-000-1995-11029-01(21196), C.P: Jaime Orlando Santofimio Gamboa. 
- Publicar la parte resolutiva de esta Sentencia en todas las Estaciones de la Policía Nacional en el Departamento de Santander por un período de seis (6) meses, y darle difusión en los diferentes medios de comunicación de circulación departamental.

- Compulsar copias ante las autoridades competentes para que se estudie si hay lugar o no a iniciar las investigaciones tanto disciplinarias, como penales en contra de aquellos funcionarios de la Policía Nacional, o del Ejército Nacional que en la época de los hechos no contribuyeron a la protección de la seguridad personal de la víctima.

- Ordenó a la Fiscalía General de la Nación informar al país, acerca de los resultados de las investigaciones adelantadas por el homicidio del político Feisal Mustafá Barbosa.

Posteriormente, en Sentencia de fecha 16 de marzo de $2012^{23}$, el Honorable Consejo de Estado, en un caso en el que se le había imputado al señor Pedro Gustavo Vásquez la violación y muerte de su hija, así como la privación injusta de la libertad por el señalamiento frente a esta conducta, argumento:

La Sala estima que se hace necesario ordenar medidas de reparación integral a favor del señor Pedro Gustavo Vásquez, como quiera que su señalamiento como responsable, sin serlo, de la violación y muerte de su menor hija, así como la privación injusta de la libertad de que fue víctima por esos hechos, constituyen una grave violación de su derecho a la honra y al buen nombre, a la libertad personal, a la honra, dignidad e intimidad familiar, consagrados en el en los Artículos 21, 28 y 42 de la Constitución Política y 7, 11 y 11.2 de la Convención Americana Sobre Derechos Humanos ${ }^{24}$, respectivamente.

[...]para la Sala, ponderados los principios de reparación integral -por razones de violaciones a derechos humanos-, con los procesales de la no reformatio in pejus y de congruencia, es claro que estos últimos tienen que ceder frente al primero, toda vez que el Estado colombiano, así como sus autoridades, no pueden sustraerse del deber jurídico superior, reiterado en diversos instrumentos, doctrina y jurisprudencia internacional (Sentencia de 20 de febrero de 2008, expediente 16996, C.P. Enrique Gil Botero; Sentencia de 21 de febrero de 2011, expediente 20046, C.P. Mauricio Fajardo Gómez).

Así, queda claro que corresponde ordenar medidas de reparación integral cuando se constata que los demandantes fueron víctimas de violación de derechos humanos, como en este caso, aunque tales medidas no hayan sido solicitadas.

23 Consejo De Estado - Sección Tercera - Radicación 25000-23-26-000-1996-02964(19807). C.P: Stella Conto Diaz Del Castillo.

24 Incorporada al ordenamiento jurídico interno mediante la Ley 16 de 1973. 
[...]la reparación integral en el ámbito de los derechos humanos supone, no sólo el resarcimiento de los daños y perjuicios que se derivan, naturalmente, de una violación a las garantías de la persona, reconocidas nacional e internacionalmente, sino que también implica la búsqueda del restablecimiento del statu quo, motivo por el cual se adoptan una serie de medidas simbólicas y conmemorativas, que propenden por la restitución del núcleo esencial del derecho o derechos infringidos.

Como se observa, el Consejo de Estado en esta providencia al encontrar probado que existió una violación a un derecho fundamental, consideró que era procedente ordenar medidas de reparación integral que inclusive no se habían pedido dentro de las pretensiones, es decir, profirió un fallo extra petita; lo cual, permite concluir que en casos donde se demuestre que existió una violación de derechos humanos, el juez de lo contencioso administrativo puede adoptar las medidas que considere necesarias para restablecer los daños a su estado original, inclusive aquellas que sean necesarias y no se hayan pedido en la demanda.

En esta oportunidad el Consejo de Estado ordenó:

- Publicar la parte resolutiva de la Sentencia, en un lugar visible, en las instalaciones de la estación de policía en que ocurrieron los hechos del 23 de febrero de 1993 o en el lugar que haga sus veces en la actualidad y en la página web de la Policía Nacional, por el término de seis (6) meses, de tal forma que toda persona que las visite, tenga la posibilidad de acceder al contenido de la misma ${ }^{25}$.

- Al Director General de la Policía Nacional informar directa y personalmente, al señor Vásquez González y a sus familiares, sobre la publicación que se ordena en el numeral anterior ${ }^{26}$.

- A la Policía Nacional brindar gratuitamente, a través de sus instituciones de salud especializadas, el tratamiento médico y psicológico requerido por el señor Pedro Gustavo Vásquez González, incluyendo los medicamentos que prescriba el médico tratante, hasta que recupere su estado de salud mental.

De otra parte, en Sentencia del 14 de junio de $2012^{27}$, en un caso en el que se

25 Supra 19: "se deberá publicar la parte resolutiva de esta providencia en todas las Estaciones de la Policía Nacional del país y darse (sic) difusión en un medio de circulación informativa del mismo".

26 En la citada Sentencia, de manera similar, se ordenó: "la realización de un acto público en donde la Policía Nacional a través de medios de comunicación masivo ofrezca disculpas públicamente a los familiares de la menor Sandra Catalina Vásquez Guzmán”.

27 Consejo de Estado - Sección Tercera - Radicación 2325000199501209-01, la Subsección B de, C.P Stella Conto Díaz del Castillo 
analizaba la responsabilidad extracontractual del Estado por el homicidio del señor Luis Armando Holguín Jurado, quien residía en una invasión y se había rehusado a retirarse de ella y cuyo propietario era un miembro del denominado grupo delincuencial "los doce apóstoles". El Consejo de Estado le da relevanciaal principio de progresividad, respecto del cual señala que, la reparación a las víctimas debe ir ascendiendo a medida que el Estado siga incurriendo en los mismos daños que con anterioridad se ha ordenado su protección en un mismo contexto social.

Igualmente, vale la pena indicar que el Consejo de Estado en esta Sentencia, reiteró la posibilidad que tiene el juez de lo Contencioso Administrativo de acudir al bloque de constitucionalidad y la jurisprudencia de la Corte Interamericana de Derechos Humanos para respaldar las medidas de reparación diferentes a las pecuniarias.

En este proveído la decisión del Máximo Tribunal Contencioso Administrativo es:

- Ordenó realizar tratamientos sicológicos para superar las secuelas que les hubiera dejado la muerte del señor Armando Holguín Jurado.

- Publicar por una vez en dos diarios de amplia circulación nacional, las consideraciones y la parte resolutiva de la Sentencia.

- Colgar el contenido total de la misma - al menos por un año en la página web del Ministerio de Defensa.

- Ordenó al Ministro de Defensa realizar un acto de reconocimiento público.

Continuando con la revisión jurisprudencial, en Sentencia del 24 de agosto de $2012^{28}$, en la que se analiza la responsabilidad del Estado por las heridas sufridas por un joven que dentro de las instalaciones de un colegio público sufrió múltiples quemaduras al manipular pólvora que estaba destinado para la celebración del cumpleaños del colegio.

En esta providencia, el Consejo de Estado acogiendo el precedente de las medidas de reparación integral y con el objeto de responder al principio de indemnidad y restitutio in integrum argumentó:

Adicionalmente, y acogiendo el precedente de la Sala que incorpora a nuestro concepto de reparación integral las denominadas medidas de reparación no pecuniarias, se ordenará, con el objeto de responder al "principio de indemnidad", al principio de la "restitutio in integrum", bajo el amparo del Artículo 16 de la ley 446 de 1998, al efecto preventivo de la responsabilidad cuando se trata de la protección de derechos de sujetos de especial protección constitucional y convencional, como es el caso de los menores de edad (con lo que se ordena el cumplimiento del Artículo

28 Consejo de Estado - Sección Tercera, Radicación 73001-23-31-000- 1999-02489 (24779), C.P. Jaime Orlando Santofimio Gamboa. 
93 constitucional y de la Convención sobre los Derechos del Niño de las Naciones Unidas)

Para tal efecto, adoptó como algunas medidas de restitución el brindar tratamientos sicológicos a las víctimas, la publicación del fallo con responsabilidad estatal, la realización de actos en el que se pidan disculpas públicas, compulsa de copias a las autoridades competentes para iniciar investigaciones disciplinarias, entre otras.

En Sentencia más reciente, del 30 de enero de $2013^{29}$, el Consejo de Estado estudió la reparación por los daños ocasionados con la fumigación de glifosato a unos predios, destacando que el principio de no reforma in pejus puede ceder cuando quiera que la situación que se pretende restablecer involucre derechos constitucionales de interés general o colectivo.

En virtud de lo anterior, el Consejo de Estado condena a la Nación para que tome medidas de reparación frente a los daños in natura cometidos con ocasión de las fumigaciones de glifosato, ordenando la ejecución de un proyecto encaminado en obtener la reforestación del bosque que se vio afectado con las fumigaciones efectuadas para la erradicación de los cultivos ilícitos del sector.

Del recuento jurisprudencial efectuado, se concluye que el H. Consejo de Estado se ha fundamentado en sus pronunciamientos de los postulados de reparación integral de perjuicios desarrollados por la Corte Interamericana de Derechos Humanos; es así, como se han garantizado medidas de reparación en situaciones en donde sin haberse visto afectados los derechos humanos, se han logrado adoptar mecanismos de protección y resarcimiento, evidenciándose un avance en la protección de los derechos e indemnización de perjuicios que se pretenden reconocer a través del medio de control de reparación directa.

Por tanto, la concepción de reparación integral hoy adoptada por el Alto Tribunal de lo Contencioso Administrativo, no debe entenderse netamente como un asunto económico sino que ha evolucionado al punto de ordenar medidas que no han sido solicitadas por la parte demandante y se encuentran encaminadas a restaurar al punto anterior al daño cualquier situación, inclusive llegando a primar las medidas de reparación frente a principios como la no reformatio in pejus.

Asi las cosas, es clara la influencia que ha tenido la Corte Interamericana de Derechos Humanos en materia de indemnización integral de perjuicios dentro del ordenamiento jurídico contencioso-administrativo colombiano, pues en sus pronuncimientos ha tomado como fundamento los postulados de reparación integral, adoptando medidas de restitución, indemnización, rehabilitación, satisfacción y garantías de no repetición (Ver apéndice 1).

29 Consejo de Estado - Sección Tercera, Radicación 18001-3-31-000-1999-00278-01 (22060), C.P: Stella Conto Diaz del Castillo. 


\section{CONCLUSIONES}

Corolario de lo anterior, es claro que en materia de indemnización integral de perjuicios, la Corte Interamericana de Derechos Humanos en sus diversos pronunciamientos ha sido enfática en establecer los lineamientos que deben seguirse a la hora de garantizar los derechos de las víctimas por la violación de los derechos humanos a la verdad, justicia, reparación y garantía de no repetición.

- Por ello, se han adoptado mecanismos de indemnización que van más allá del aspecto netamente económico, tendientes a brindar una atención especial a las víctimas y que permitan el restablecimiento de las afectaciones de carácter psicológico, social, afectivo, entre otros, que se hayan generado por la comisión de una conducta estatal en la que se hayan afectado los derechos humanos.

- En ese sentido, el Consejo de Estado ha adoptado una posición acorde a las modalidades de reparación desarrolladas por la Corte Interamericana de Derechos Humanos y en efecto, ha implementados medidas de restitución, indemnización, rehabilitación, satisfacción y garantías de no repetición.

- Asimismo, es posible afirmar que para el Consejo de Estado es posible adoptar una decisiónextra petita y ultra petita en medios de control de reparación directa en asuntos por vulneraciones de Derechos Humanos.

- Es por ello, que el Juez de lo Contencioso Administrativo se encuentra en la posibilidad de adoptar medidas de satisfacción similares a las adoptadas por la Corte Interamericana de Derechos Humanos, en los casos donde se vean afectados los derechos de dicha naturaleza, en aras de garantizar una adecuada indemnización a las víctimas.

- Igualmente, cabe señalar que de acuerdo a los pronunciamientos del máximo Tribunal de lo Contencioso Administrativo en Colombia, el principio de la no reformatio in pejus puede ceder frente a la reparación integral por vulneración de derechos humanos.

- Por último, es del caso precisar que aunque el Consejo de Estado le ha dado un tratamiento diferenciador a las reparaciones con ocasión a vulneraciones de derechos humanos, especialmente en relación con la rehabilitación y garantía de no repetición, de acuerdo con el principio de progresividad y la Sentencia con numero interno 19031 de 2011, es posible que el Consejo de Estado acuda a otras medidas de reparación diferentes a las tradicionales, siempre y cuando a través del debate se logre demostrar que con estas medidas se está reparando proporcionalmente con el daño a la víctima.

- Asi las cosas, es clara la influencia que han tenido los múltiples fallos de la Corte Interamericana de Derechos Humanos en los pronunciamiento del Consejo de Estado en lo que respecta al medio de control de reparación directa. 


\section{REFERENCIAS}

\section{Jurisprudencia Colombiana}

Andrade, H. (2011). Consejo de Estado. Número Interno: (20496) Proceso radicado No 19001-23-31-000-1996-03006-01, Sentencia del doce (12) de mayo de dos mil once (2011).

Conto Díaz del Castillo, S. (2012). Número Interno (21884) Proceso radicado 0500123-25-000-1995-01209-01, Sentencia del catorce (14) de junio de 2012.

Conto Díaz del Castillo, S. (2012). Número Interno: (22748) Proceso radicado No: 17001-23-31-000-1999-00092-01, Sentencia del treinta (30) de enero de dos mil doce (2012).

Correa, R.E. (2007). Consejo de Estado. Número Interno: (15494) Proceso radicado No: 15001-23-31-000-1994-04691-01, Sentencia del veintinueve (29) de agosto de dos mil siete (2007).

Correa Palacio, R.E. (2007). Consejo de Estado. Número Interno 16460 Proceso radicado No 25000-23-26-000-1990-06968-01, Sentencia del seis (6) de junio de dos mil siete (2007).

Gil, E. (2010).Consejo de Estado. Número Interno: (18357) Proceso radicado No: 18001-23-31-000-1997-01198-01, Sentencia del dieciocho (18) de marzo de dos mil diez (2010).

Giraldo Gómez, M. E. [Ponente] (2000), Consejo de Estado. Número Interno: (11945) Proceso radicado No. 520012331000020001194501, Sentencia del dos (2) de marzo de dos mil (2000).

Santofimio Gamboa, J.O. (2011). Consejo de Estado. Número Interno: (19976) Proceso radicado No: 54001-23-31-000-1994-08654-01, Sentencia del nueve (9) de mayo de dos mil once (2011).

Santofimio Gamboa, J.O. (2012). Consejo de Estado Número Interno: (21196) Proceso radicado No: 68001-23-15-000-1995-11029-01, Sentencia del dieciocho (18) de enero de dos mil doce (2012).

Uribe, J. C. [Ponente] (1991). Consejo de Estado, Sala de lo Contencioso Administrativo, Sección Tercera, Número Interno (6454), Sentencia del Junio veintisiete (27) de mil novecientos noventa y uno (1991).

\section{Sentencias}

Corte Constitucional. Sentencia C-225-95 M.P: Alejandro Martínez Caballero. Corte Constitucional. Sentencia C-578-95 M.P: Eduardo Cifuentes Muñoz. Corte Constitucional. Sentencia C-358-97 M.P: Eduardo Cifuentes Muñoz. Corte Constitucional. Sentencia C-191-98 M.P: Eduardo Cifuentes Muñoz. 


\section{Jurisprudencia Internacional}

Corte Interamericana de Derechos Humanos

Caso: Garrido y Baigoria Vs. Argentina Sentencia de 2 de febrero de 1996.

Caso Paez Vs. Perú Sentencia del 3 de noviembre de 1997.

Caso: Las Palmeras Vs. Colombia. Sentencia del 26 de noviembre de 2002.

Caso: Masacre de Mapiripán Vs. Colombia. Sentencia del 15 de septiembre de 2005.

Caso: 19 comerciantes Vs. Colombia. Sentencia del 5 de julio de 2004.

Caso: Gutiérrez Soler Vs. Colombia. Sentencia del 12 de septiembre de 2005.

Caso: Ituango Vs. Colombia. Sentencia del 01 de julio de 2006.

\section{Normatividad Colombiana}

Constitución Política de Colombia (1991).Gaceta Constitucional (116).

Ley 16 de 1972 por medio de la cual se aprueba la Convención Americana sobre Derechos Humanos "Pacto de San José de Costa Rica", firmado en San José, Costa Rica, el 22 de noviembre de 1969”, Diciembre 30.Diario Oficial 33.780.

\section{Doctrina Nacional}

Alviar, H. (2009). Manual de derecho administrativo. Bogotá: Editorial Temis.

Henao, J. (2007).Análisis comparativo de la responsabilidad extracontractual del Estado en derecho colombiano y francés. Bogotá: Editorial Universidad Externado de Colombia.

Motta, D. (2010). Responsabilidad del Estado colombiano frente al derecho a la reparación en el Sistema Interamericano de los Derechos Humanos protección y garantía, en: Criterio Jurídico Grantista. Bogotá: Universidad Autónoma de Colombia.

Reina, O. (2009). La responsabilidad internacional del Estado colombiano en la jurisprudencia de la Corte Interamericana de Derechos Humanos, en Revista IUSTITIA (7). Universidad Santo Tomas. Bucaramanga - Colombia, 69 - 92.

Rodríguez, L. (2007). Derecho administrativo, General y Colombiano, $15^{\mathrm{a}}$ ed., Bogotá: Editorial Temis.

Quintero, G. (2009). La construcción de la responsabilidad del Estado en Colombia: entre la Dualidad de Jurisdicciones y la Dualidad Jurídica, Bogotá: Ediciones Uniandes. 


\section{Doctrina Internacional}

Alessandri A. (1981). De la responsabilidad extracontractual en el derecho civil. Santiago de Chile, Chile: Imprenta Universal.

Diccionario de la Real Academia Española. Disponible en: http:/rae.es/rae.html. Naciones Unidas. Disponible en: http://www.un.org/es/globalissues/humanrights/.

\section{Documentos Complementarios}

Ley 1437 de 2011, 02 de julio de 2012, Diario Oficial 47.956 de enero 18 de 2011.

Cassagne, J y otros. (2009). Responsabilidad del Estado. Buenos Aires, Argentina: Editorial Rubinzal - Culzoni.

Quintero, G. (2004). Responsabilidad del Estado derivada de la actividad Tributaria en Derecho Colombiano - Contencioso Tributario hoy, jornadas internacionales. Caracas, Venezuela: Editorial Fundación Estudios de Derecho AdministrativoAsociación Venezolana de Derecho Tributario.

Quintero, G. (2004). Incidencias del Código de Napoleón en la adopción de un criterio de responsabilidad para las personas públicas en el derecho colombiano. Comentarios acerca del origen de la responsabilidad de las personas públicas Revista de Derecho Privado (3). Diciembre 2004. Bogotá: Editorial Uniandes, 79-93.

Scognamiglio, R. (1996). El daño moral, contribución a la teoría extracontractual, Bogotá: Editorial Universidad Externado de Colombia.

Tamayo, J. (2000). La responsabilidad del Estado, el daño antijurídico (CP. Art 90 el riesgo excepcional y las actividades peligrosas). Bogotá: Editorial Temis. 


\section{APÉNDICE}

Tabla 1. Grado de Influencia

\begin{tabular}{|c|c|c|}
\hline Medidas de Reparación ${ }^{1}$ & $\begin{array}{c}\text { Corte Interamericana } \\
\text { de Derechos } \\
\text { Humanos }\end{array}$ & $\begin{array}{l}\text { Consejo de } \\
\text { Estado }\end{array}$ \\
\hline Publicación de Sentencia. & $\mathrm{X}$ & $\mathrm{X}$ \\
\hline Disculpas públicas. & $\mathrm{X}$ & $\mathrm{X}$ \\
\hline $\begin{array}{l}\text { Adelantar investigaciones por parte de la Fiscalía General } \\
\text { de la Nación. }\end{array}$ & $\mathrm{X}$ & $\mathrm{X}$ \\
\hline $\begin{array}{l}\text { Oficiar para iniciar investigaciones disciplinarias y } \\
\text { penales. }\end{array}$ & & $\mathrm{X}$ \\
\hline Fiscalía informe de las actuaciones adelantadas. & $\mathrm{X}$ & $\mathrm{X}$ \\
\hline $\begin{array}{l}\text { Director de la Policía emitir circular actualizando } \\
\text { procedimientos de traslados de uniformados a sitios } \\
\text { especialmente peligrosos. }\end{array}$ & & $\mathrm{X}$ \\
\hline $\begin{array}{l}\text { Ordenar al Estado que a través de canales diplomáticos } \\
\text { solicite iniciar investigaciones de violaciones de DD.HH. } \\
\text { por parte del ELN. }\end{array}$ & & $\mathrm{X}$ \\
\hline Tratamiento médico y sicológico. & $\mathrm{X}$ & $\mathrm{X}$ \\
\hline $\begin{array}{l}\text { Realizar labores de identificación y establecer el paradero } \\
\text { de restos mortales de personas no identificadas, además } \\
\text { de realizar exhumación de los mismos y hacer entrega } \\
\text { de restos a los familiares para que den una adecuada } \\
\text { sepultura y estos gastos a cargo del Estado. }\end{array}$ & $\mathrm{X}$ & \\
\hline $\begin{array}{l}\text { Realizar gestiones tendientes a la ubicación de personas } \\
\text { no identificas. }\end{array}$ & $\mathrm{X}$ & \\
\hline Monumentos en memorias de las víctimas. & $\mathrm{X}$ & \\
\hline $\begin{array}{l}\text { Aplicación de la jurisprudencia del sistema interamericano } \\
\text { de DD.HH en la justicia penal militar. }\end{array}$ & $\mathrm{X}$ & \\
\hline $\begin{array}{l}\text { Fortalecimiento de los controles de seguridad en centros } \\
\text { de detención. } \\
\text { Establecer un mecanismo que permita realizar el } \\
\text { seguimiento oficial de las reparaciones ordenadas a las } \\
\text { víctimas. } \\
\text { Garantías estatales de seguridad para regresar a las } \\
\text { víctimas de desplazamiento forzado que deseen regresar } \\
\text { a sus lugares de origen. }\end{array}$ & $\mathrm{X}$ & $\mathrm{X}$ \\
\hline Fijar una placa en un lugar público. & $\mathrm{X}$ & \\
\hline $\begin{array}{l}\text { Ejecutar un proyecto de reforestación con especies } \\
\text { maderables propias de la región, como el cedro, achapo, } \\
\text { nogal, balso, carbonero, ahumado, etc. }\end{array}$ & & $\mathrm{X}$ \\
\hline
\end{tabular}




\begin{tabular}{|c|c|}
\hline \multirow{2}{*}{$\begin{array}{l}\text { Verificar que el establecimiento educativo cumple con lo } \\
\text { exigido por la ley y manual de convivencia; } \\
\text { las autoridades nacionales, departamentales y locales } \\
\text { competentes deberán verificar el cumplimiento de todas } \\
\text { las normas sanitarias, de seguridad industrial y de salud } \\
\text { ocupacional a que hace mención esta providencia, sin } \\
\text { perjuicio de aquellas que las sustituyan, modifiquen } \\
\text { o adicionen en la actualidad, en todas las instituciones } \\
\text { académicas del país. }\end{array}$} & $\mathrm{X}$ \\
\hline & $X$ \\
\hline $\begin{array}{l}\text { Informar por conducto del Tribunal Administrativo } \\
\text { las medidas incorporadas en materia de prohibición de } \\
\text { disposición, uso y manipulación de sustancias explosivas } \\
\text { y pirotécnicas en los laboratorios y demás instalaciones } \\
\text { de todas las instituciones educativas del país. }\end{array}$ & $\mathrm{X}$ \\
\hline $\begin{array}{l}\text { El Departamento del Tolima deberá proceder a la revisión } \\
\text { especial de todos los laboratorios de los colegios públicos } \\
\text { y privados de su jurisdicción, tanto el cumplimiento } \\
\text { de las normas de seguridad como de infraestructura y } \\
\text { dotación de los laboratorios. }\end{array}$ & $\mathrm{X}$ \\
\hline $\begin{array}{l}\text { La expedición, por parte del Ministerio de Educación } \\
\text { Nacional, de un manual de utilización de laboratorios } \\
\text { (de física o química) haciendo énfasis en las medidas } \\
\text { de seguridad que deben observarse y de las sanciones } \\
\text { disciplinarias por su incumplimiento. }\end{array}$ & $X$ \\
\hline $\begin{array}{l}\text { El Ministerio de Educación, las Secretarías } \\
\text { Departamentales (o Seccionales) de Educación y a todas } \\
\text { las instituciones educativas del país, procederán a la } \\
\text { adecuación a normas técnicas de uso de los laboratorios, } \\
\text { normas de seguridad industrial, implementos de } \\
\text { protección (batas, calzado adecuado, guantes, etc) de } \\
\text { los laboratorios que existen al interior de los centros } \\
\text { educativos. }\end{array}$ & $\mathrm{X}$ \\
\hline $\begin{array}{l}\text { Se recomienda como medida preventiva la verificación } \\
\text { de las condiciones sanitarias. }\end{array}$ & $\mathrm{X}$ \\
\hline $\begin{array}{l}\text { El Ministerio de Educación y al Departamento del } \\
\text { Tolima realizará campañas preventivas en instituciones } \\
\text { educativas del mismo orden del "Colegio Nacional San } \\
\text { Simón", respecto a la no utilización de pólvora, sustancias } \\
\text { pirotécnicas o explosivas por los menores de edad en } \\
\text { todas los establecimientos educativos. }\end{array}$ & $X$ \\
\hline
\end{tabular}

Fuente: Los autores.

1 Consejo de Estado - SeccionTercera,Radicación 05001-23-25-000-1995-01209-01(21884); 0500123-31-000-1993-01886-01(18850);18001-23-31-000-1999-00278-01(22060);25000-23-26-0001996-0296401(19807); 54001-23-31-000-1994-08357-01(21274); 54001-23-31-000-1997-0278001(19959); 68001-23-15-000-1995-11029-01(21196) y 73001-23-31-000-1999-02489-01(24779) 
